\title{
Evaluation of mental representation for same and mixed compatibility assignments
}

\author{
LANIE A. DORNIER \\ Texas Tech University, Lubbock, Texas \\ and \\ T. GILMOUR REEVE \\ Auburm University, Auburm, Alabama
}

\begin{abstract}
In most studies of stimulus-response (S-R) compatibility, assignments within a set are either compatible or incompatible for all S-R combinations. The present study provided an extension of previous research by examining the situations with same or mixed $S-R$ assignments for pairs of subsets from a four-choice spatial precuing task. Assignments of stimuli to responses for the subsets could be same (both subsets assigned compatibly or both assigned incompatibly) or mixed (one subset assigned compatibly and one subset assigned incompatibly). A precue stimulus provided advanced information about which subset, and thus which assignment, would be required for responding on each trial. Experiment 1 had four visual stimuli assigned to four response locations, whereas Experiment 2 had the four visual stimuli assigned to only two response locations. For both experiments, the analyses revealed similar patterns of reaction times, with reaction times slower in the mixed condition than in the same condition. Moreover, the reaction times for the compatible assignments in the mixed sets were slowed more than the incompatible ones in those sets. The nonprecued subset influenced the S-R translation processes, indicating that the nonprecued subset was part of the mental representation upon which subjects were making decisions.
\end{abstract}

Stimulus-response (S-R) compatibility refers to the extent to which stimuli and responses are linked in a natural way (Fitts \& Seeger, 1953; Proctor \& Reeve, 1990; Simon, 1969; Umiltà \& Nicoletti, 1990). Research studies examining compatibility effects have used a variety of tasks (i.e., spatial, symbolic, and semantic) with varying degrees of correspondence between stimulus and response sets and elements within each set (see Proctor \& Reeve, 1990). Kornblum, Hasbroucq, and Osman (1990) have proposed a model of S-R compatibility to explain previously considered unrelated effects (i.e., spatial, symbolic, or semantic tasks) "in terms of common basic cognitive mechanisms" (p. 1). Although it is beneficial to develop a model encompassing a variety of tasks, it is also beneficial to examine the variety of compatibility effects that are present within a given task.

In choice-task situations, reaction times increase as the compatibility, or naturalness, between stimuli and responses decreases (Fitts \& Seeger, 1953: Leonard, 1959; Wallace, 1971). In recent research on compatibility effects, twochoice tasks have been used (e.g., Dutta \& Proctor, 1992;

The authors would like to thank Greg Hancock for his insight with the statistical analyses. We would also like to thank two anonymous reviewers and the editor. Art Kramer, for their helpful comments on an earlier version of the manuscript. T.G.R. is affiliated with the Motor Behavior Center at Auburn. Correspondence concerning this article should be addressed to L. A. Dornier, Texas Tech University, Department of Health, Physical Education, and Recreation, Men's Gym, Box 43011, Lubbock, TX 79409-301! (e-mail: pllad@ttacs.tu.edu).
Heister, Schroeder-Heister, \& Ehrenstein, 1990; Ladavas, 1990; Nicoletti \& Umiltà, 1985; Weeks \& Proctor, 1990). Explanations for the compatibility effects in two-choice tasks have emphasized the importance of mental spatial coding of the S-R sets (Heister et al., 1990; Ladavas, 1990; Umiltà \& Nicoletti, 1990; Wallace, 1971). Evidence for spatial coding has been shown for situations in which the stimulus and response sets are positioned at the body midline and for situations in which either or both of the sets are positioned to one side of the body (Ladavas \& Moscovitch, 1984; Nicoletti, Anzola, Luppino, Rizzolatti, \& Umiltà, 1982). For two-choice spatial tasks, the critical feature, in terms of S-R compatibility, is the assignment between the spatial locations, because the mental codes are based on the relative spatial locations of the stimulus and response sets.

For more complex tasks, researchers have examined compatibility effects by using a movement precuing procedure (Dornier \& Reeve, 1990; Larish, 1986; Proctor \& Reeve, 1986; Reeve \& Proctor, 1984). With the precuing procedure, the experimenter can manipulate the amount of response uncertainty on each trial. Information about none, some, or all of the response alternatives can be provided before the imperative stimulus is presented. A basic assumption of this procedure is that the subject readies the precued information so that the reaction time indicates the time to specify the response components that have not been precued. Although the precue procedure has been used to examine response programming of movements (Klapp, 1977; Rosenbaum, 1980, 1983), other researchers 
have attributed the precuing benefits (differential reaction time patterns for specific precues) to translation processes, rather than programming processes (Dornier \& Reeve, 1990; Goodman \& Kelso, 1980; Larish, 1986; Reeve \& Proctor, 1984, 1985). In other words, it has been shown that the precuing procedure is effective for examining compatibility effects (Reeve \& Proctor, 1990).

As with the two-choice task, the compatibility effects found with the more complex tasks in precuing studies support a spatial coding explanation. For example, Reeve and Proctor (1984) had subjects perform with the middle and index fingers of each hand and found that relative precuing benefits were a function of the precued location and not the specific fingers being precued. That is, the precues that specified left-most and right-most spatial locations provided the fastest reaction times for the S-R set, regardless of the specific fingers assigned to the required location. In a related study, Proctor and Reeve (1986) used a vertical, rather than a horizontal, hand placement and, once again, concluded that coding of the S-R set was based on the spatial locations.

Additional support for a coding account of the precuing effect is evident in the pattern of reaction times across precue intervals. The precue interval is the period of time from the onset of a precue until the onset of the imperative stimulus (Rosenbaum, 1983). In this interval, the subject should use the information from the precue to select the upcoming response. Reeve and Proctor $(1984,1985)$ found benefits for precues indicating the left/right locations at short intervals, but at long intervals all combinations of precued stimuli (left/right and inner/outer stimulus lights) had similar reaction times. This finding suggests that some $S-R$ subsets indicated by the precue (i.e., inner vs. outer stimuli) required more translation time than did other precued subsets (i.e., left vs. right stimuli). This result is consistent with the compatibility interpretation of the precuing effect (Reeve \& Proctor, 1990). The difficulty of the translations that are necessary for selecting a response are determined by the mental codes used to represent the spatial locations of the stimulus and response sets and the correspondence between the codes (Proctor \& Reeve, 1988; Proctor, Reeve, \& VanZandt, 1992; Umiltà \& Nicoletti, 1990).

The present study extends from the compatibility studies in which the precuing procedure has been used (e.g., Reeve \& Proctor, 1984) by incorporating both compatible and incompatible assignments within the S-R set. For example, in a four-choice task involving the index and middle fingers of the left and right hands, the relationship between the S-R subsets for each hand can be "same" or "mixed." The condition would be "same" if the left-hand subset and the right-hand subset were assigned both compatibly (the four stimulus locations corresponding directly to the four response locations) or both incompatibility (the four stimulus locations corresponding indirectly, or crossed, to the four response locations). That is, the assignment could be compatible for finger responses from both the left-hand and the right-hand subsets, or incompatible for both subsets. The condition would be "mixed" if one subset was assigned compatibly and the other subset assigned incom- patibly. That is, the finger responses from the left hand could be assigned compatibly and the finger responses from the right hand assigned incompatibly, or vice versa. The mixing of compatible and incompatible assignments within an S-R set may affect the mental coding and time required for the translation processes to operate.

Much of the research on compatibility effects has used assignments that are compatible or incompatible for the entire $\mathrm{S}-\mathrm{R}$ set. That is, each $\mathrm{S}-\mathrm{R}$ assignment is compatible or incompatible for all the elements within the ensemble. An exception to this basic approach was the research by Duncan (1977a, 1977b, 1978), who varied the S-R ensemble by manipulating the consistency between stimulus and response mapping. Subjects were required to respond to stimuli that were mapped consistently (all compatible or all incompatible mapping of stimuli to responses; similar to the "same" condition as defined above) or inconsistently (some compatible and some incompatible mapping of stimuli to responses; similar to the "mixed" condition as defined above). Duncan found that reaction times were slower for inconsistent mapping than for consistent mapping. Duncan concluded that the consistent mapping task could use the same transformation for all pairs of stimuli and responses. For the inconsistent mapping, several alternatives were possible for a correct transformation, thus increasing the time to choose a response. Duncan concluded that response decisions are not based on individual $\mathrm{S}-\mathrm{R}$ associations but on rules that reflect the entire set of S-R pairs (i.e., a unified representation of the set). Because the task in Duncan's experiments required decisions about all S-R sets to be made after the imperative stimulus, the finding supporting a unified representation was to be expected. That is, subjects were encouraged to use information from all $\mathrm{S}-\mathrm{R}$ pairs in the representation because no advanced information was available to reduce the set size.

As an extension to Duncan's study, providing advanced (i.e., precued) information would allow further examination of how S-R ensembles are represented and how decisions are made. That is, providing advanced information about which subsets will be part of the imperative stimulus should allow subjects to use only that subset representation rather than be influenced by the entire set. The use of only the subset representation should be further enhanced if subjects received sufficient time to process the advanced information (i.e., long precue intervals). Thus, examining how conditions (same or mixed), assignments (compatible or incompatible), and intervals interact is an appropriate test for determining whether precued subsets can be represented without influence from a noncued subset.

In the present study, precues were provided, which reduced the set size from which the response decisions would be made. The study examined whether subjects could, in fact, eliminate the subset that was not precued from the mental representation upon which decisions are made. For the mixed (inconsistent) condition in the present study, the precue would specify only one assignment (either compatible or incompatible) for that precued S-R pair, thus making the final response decision on the basis of that as- 
signment. If representation of the $S-R$ set is unified in nature as Duncan proposed, the precue interval should not influence the results. That is, the results should be similar for the short and long precue intervals, supporting Duncan's unified representation. On the other hand, if representation of the $S-R$ set is hierarchical in nature, then, at short precue intervals, subjects should not have enough time to process advanced information from the precue, and results should be similar to Duncan's results. However, at longer precue intervals, subjects should be able to use advanced information to eliminate the nonprecued part of the total set. And the results should be different.

The purpose of the present study was to examine spatial compatibility effects within complex precuing situations. In Experiment 1, compatibility effects were examined in a complex four-choice task. In Experiment 2, compatibility effects were also examined with the precuing procedure, but with a reduced response set size. In the second experiment, the $\mathrm{S}-\mathrm{R}$ arrangement had four visual stimuli but only two response keys. The use of the reduced response set size provides information about whether the representation of the S-R set is altered by assigning different stimulus sets to the same responses. Taken together, the two experiments evaluated mental coding within complex S-R sets.

\section{EXPERIMENT 1}

In Experiment 1, compatibility effects were examined as a function of the nature of the subsets and the length of the precue interval. A four-choice movement precuing task was used, similar to that used by Reeve and Proctor (1984). In the previous studies done with this task, the assignment of stimuli to responses has been compatible (i.e., the four stimulus locations have corresponded directly to the four response locations). The patterns of reaction times obtained previously have been attributed to S-R compatibility effects in the translation processes (Reeve \& Proctor, 1990). In Experiment 1, the findings of these studies were extended by the use of incompatible assignments and the combination of compatible and incompatible assignments within a set. Examination of the pattern of reaction times obtained in these conditions provides evidence for the type of mental coding that is used for complex precuing situations (Duncan, 1977a, 1977b, 1978).

\section{Method}

Subjects. Subjects were 16 students from the university population who volunteered to participate in the study. Each subject received information regarding the nature of the expcriment and signed informed consent forms.

Apparatus. The apparatus consisted of a visual display and a response panel (see Figure 1). The apparatus was interfaced with a TRS-80 Model IIl computer, which controlled stimulus presentations and recorded reaction times and performance errots. Reaction time was measured in milliseconds. The visual display measured $53 \times 53 \mathrm{~cm}$ and consisted of six stimulus lights $(.5 \mathrm{~cm}$ in diameter $)$ arranged in two rows. In the first row, two lights were placed $12 \mathrm{~cm}$ apart. The second row was located $8 \mathrm{~cm}$ below the first row and contained four lights. These four lights were each $6 \mathrm{~cm}$ apart. The left-

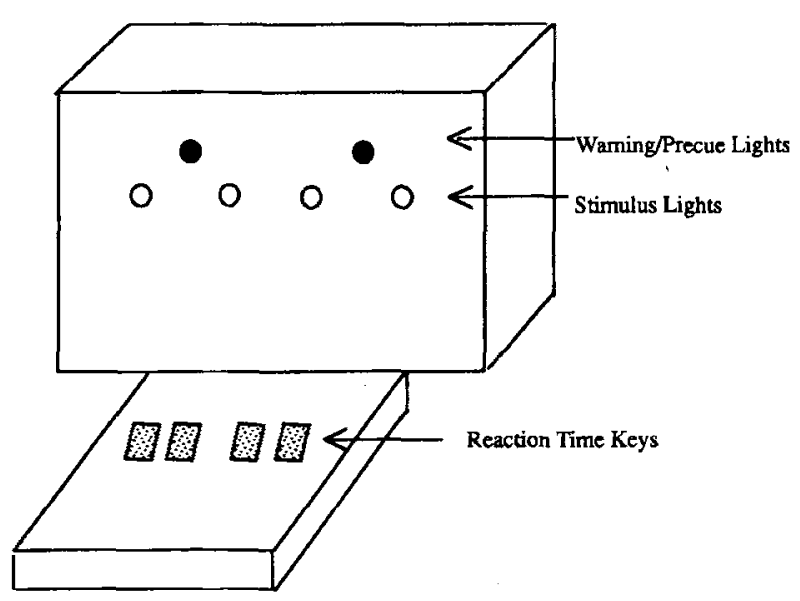

Figure 1. Stimulus-response apparatus used in Experiment 1.

most light in the first row was centered above the two left-most lights on the second row. The right-most light in the first row was centered above the two right-most lights in the second row. The lights in the first row served as the warning and precue stimuli, and the lights in the second row served as the target stimuli.

The response panel measured $36 \times 27 \mathrm{~cm}$ and consisted of four response keys located $4 \mathrm{~cm}$ apart and centered in front of the visual display. Each target key contained a wooden block base with a target pad $(1 \times 2 \mathrm{~cm})$ on which the subjects placed their index and middle fingers of the left and right hands. Hand placement was normal, with left-to-right ordering of fingers as left middle, left index, right index, and right middle.

Precues, assignments, and conditions. Subjects were given a precue on each trial that reduced the four-choice task to a two-choice task. The onset of the left precue indicated that the target would be one of the two left-most targets, and the onset of the right precue indicated that the target would be one of the two right-most targets. Thus, the precue created an $\mathrm{S}-\mathrm{R}$ subset that comprised either the two left-most or the two right-most stimuli and responses.

When a compatible assignment for a subset was used. a direct correspondence between stimulus and response locations existed. As an example of a compatible assignment, when the precue indicated the two left-most stimulus locations, the response was assigned so that the middle finger of the left hand (the left-most response) was paired with the left-most target stimulus in the subset and the index finger of the left hand (the right-most response on the left hand) was paired with the right-most target stimuli in the subset. When an incompatible assignment for a subset was used, an indirect, or crossed, assignment between stimulus locations and response locations existed within that subset. As an example of an incompatible assignment, when the precue indicated the two left-most stimulus locations, the response was assigned so that the middle finger of the left hand (i.e., the left-most response on the left hand) was paired with the rightmost stimulus in the subset and the index finger of the left hand (i.e., the right-most response on the left hand) was paired with the leftmost stimulus in the subset. Similar relationships existed for the compatible and incompatible assignments when the precue indicated the two right-most stimuli and thus, the responses from the right hand. All subjects participated in four blocks of trials. In two blocks, the assignment of stimuli to responses was the same; that is, subjects were given either a compatible or an incompatible assignment for both $\mathrm{S}-\mathrm{R}$ subsets. In the other two blocks, the assignment of stimuli to responses was mixed; that is, subjects were given a compatible assignment for the responses on one hand and an incompatible assignment for the responses on the other hand. The two blocks with mixed assignments allowed for all combinations of assignments to 
occur across the left and right hands. That is, for one mixed block, the assignment was compatible for the left hand and incompatible for the right hand and for the other mixed block the assignment was vice versa. Order of presentation of blocks was random, with subjects participating in one block per day on 4 consecutive days.

Procedure. Upon entering the test room, subjects were given written instructions that explained the nature of the experiment and the testing procedure. Subjects also were asked to read and sign informed consent forms. Subjects were seated in front of the stimulus display and response panel so that the midline of the body was centered before the apparatus.

Subjects completed one block of trials for 4 consecutive days. For each of the four blocks, subjects had a total of 180 trials, with 40 test trials at each target stimulus preceded by 20 practice trials. A trial consisted of a 500-msec warning stimulus (onset of both lights on the top row), followed $1 \mathrm{sec}$ later by the precue (onset of either the left or the right light on the top row), and then a variable precue interval of 0 (simultaneous onset of precue and target), 750, 1,500, or $3,000 \mathrm{msec}$, followed by the imperative stimulus. The imperative stimulus remained on until the subject responded.

Presentations of precue and target stimuli were random, with the restriction that a specific stimulus could not occur on more than three consecutive trials. Each precue interval occurred randomly, 10 times for each target, with the restriction that the same interval could not occur on more than three consecutive trials.

Design and analysis. Reaction times and response errors were obtained from each subject as a function of condition (same or mixed), assignment (compatible or incompatible), hand (left or right), finger (index or middle), and precue interval $(0,750,1,500$, and $3,000 \mathrm{msec}$ ). Reaction time data were analyzed in a 2 (condition) $\times 2$ (assignment) $\times 2$ (hand) $\times 2$ (finger) $\times 4$ (precue interval) analysis of variance with repeated measures on all factors.

Errors could be one of two types: response errors or time constraint errors. Response errors consisted of incorrect responses, such as when a subject responded with the left middle finger when the correct response would have been made with the left index finger. Reaction times over $1,000 \mathrm{msec}$ or under $100 \mathrm{msec}$ were considered time constraint errors. Trials involving errors were excluded from the reaction time analysis. Because errors were low (less than $1 \%$ ), no analysis was performed on the error data.

\section{Results}

The analysis of reaction time data indicated a significant main effect for all five factors: condition $[F(1,15)=$ $55.9, p<.01$; means of 399 and $482 \mathrm{msec}$ for same and mixed, respectively $]$; assignment $[F(1,15)=61.7, p<.01$; means of 412 and $469 \mathrm{msec}$ for compatible and incompatible, respectively]; hand $[F(1,15)=8.02, p<.01$; means of 435 and $446 \mathrm{msec}$ for right and left, respectively]; finger $[F(1,15)=9.49, p<.01$; means of 435 and $446 \mathrm{msec}$ for index and middle, respectively]; and interval $[F(3,45)=$ $177.3, p<.01$; means of $558,424,339$, and $382 \mathrm{msec}$ for $0,750,1,500$, and $3,000 \mathrm{msec}$, respectively]. All factors were also involved in higher order interactions.

One significant interaction involved condition $\times$ assignment $[F(1,15)=5.07, p<.05]$. As indicated in Figure 2, the difference between the compatible and incompatible assignment is greater in the same condition (difference = $75 \mathrm{msec}$ ) than in the mixed condition (difference $=40 \mathrm{msec}$ ). Also note in Figure 2 that the reaction times for the compatible assignment in the mixed condition are actually slower than the reaction times for the incompatible as-

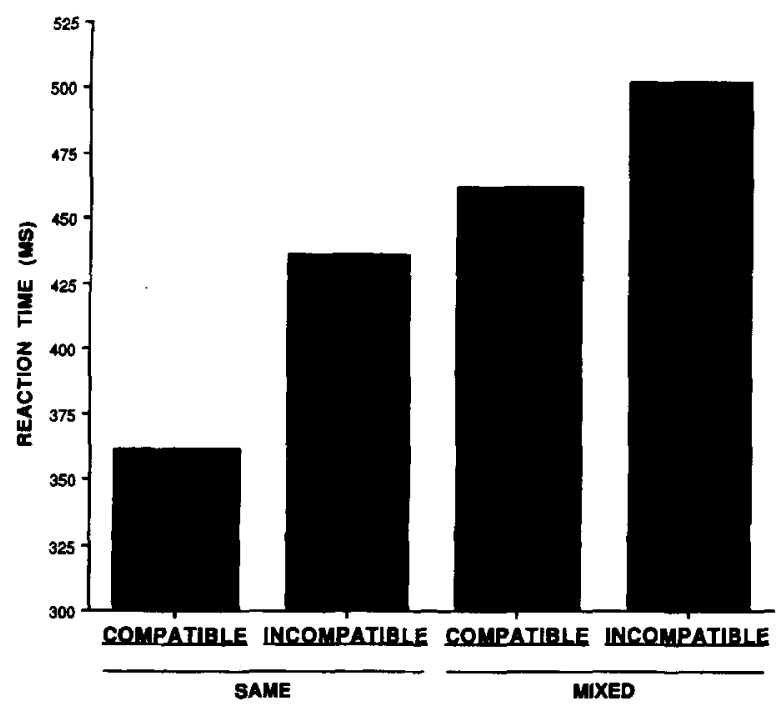

Figure 2. Mean reaction times as a function of condition (same/ mixed) and assignment (compatible/incompatible) in Experiment 1.

signment in the same condition. The three-way interaction for condition $\times$ assignment $\times$ interval was not significant $[F(3,45)=1.46, p>.05]$. Thus, this pattern of reaction times did not change across the precuing intervals. The mixed condition caused an additional slowing of reaction times because of additional translation processes that are required when both compatible and incompatible assignments are present (Duncan, 1977a, 1978).

A second significant interaction was that of condition $X$ interval $[F(3,45)=26.36, p<.01]$. This was due to the greater difference in reaction times between the same and mixed conditions at the short intervals than at the long intervals, the differences being $151,76,56$, and $51 \mathrm{msec}$ for intervals of $0,750,1,500$, and $3,000 \mathrm{msec}$, respectively (see Figure 3). With short precue intervals, the initial translation processes most likely occur during the reaction time interval, rather than in the precue interval, causing an increase in reaction times, whereas with long precue intervals, the translation processes most likely are completed during the precue interval, resulting in faster reaction times. It seems, as with the condition $\times$ assignment interaction, that the mixed condition requires more translations in selection of the proper response subset because both compatible and incompatible assignments were present. However, even with a long precue interval, the effect of the mixed condition on the reaction times is still evident.

A third significant interaction was that of assignment $x$ interval $[F(3,45)=3.46, p<.05]$. Reaction times were slower for the incompatible than for the compatible assignments, and this difference was greater at short precue intervals, with the differences being 74, 59, 54, and $43 \mathrm{msec}$ for intervals of $0,750,1,500$, and $3,000 \mathrm{msec}$, respectively (see Figure 4). Similar to the condition $\times$ interval interaction, this interaction is due to more difficult translations 


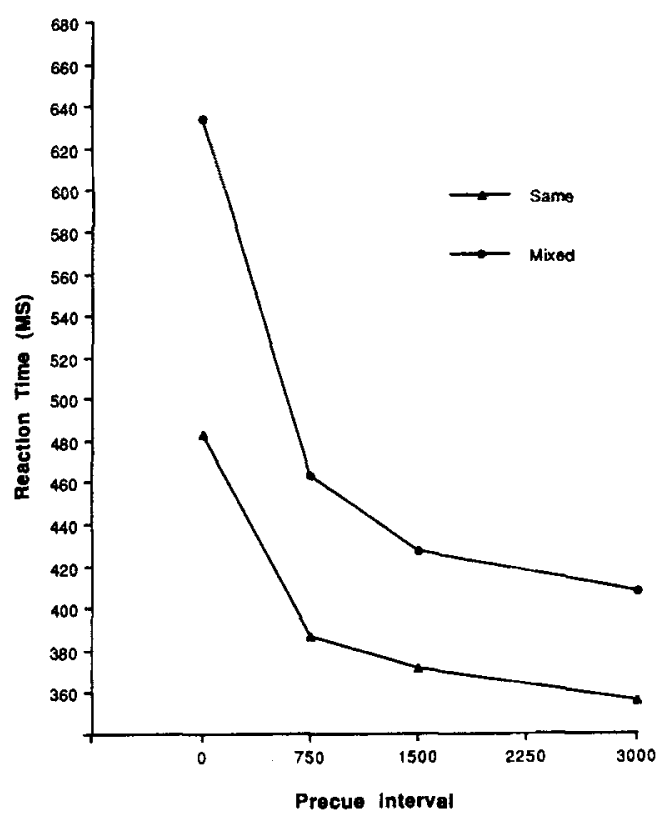

Figure 3. Mean reaction times as a function of condition (same/ mixed) and precue interval in Experiment 1.

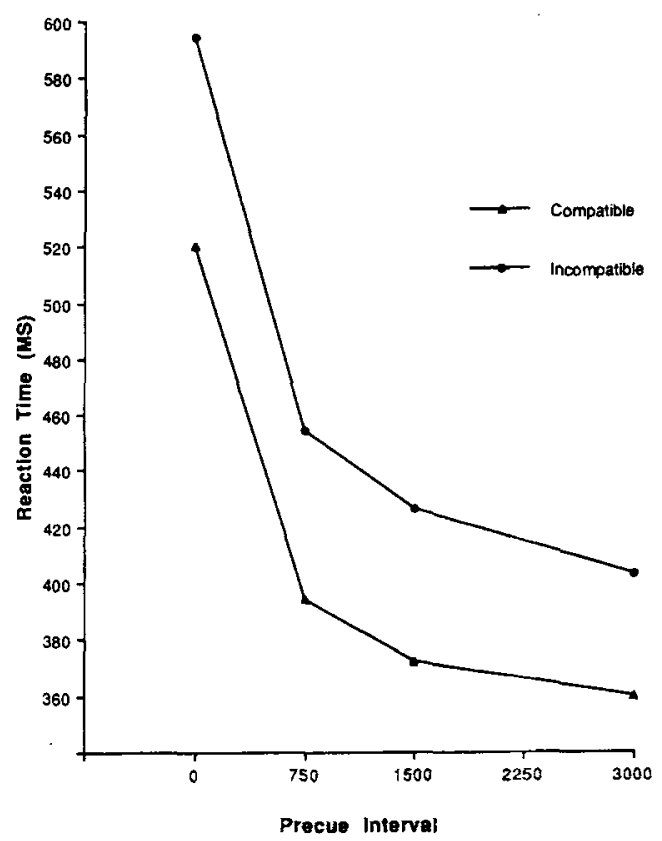

Figure 4. Mean reaction times as a function of assignment (compatible/incompatible) and precue interval in Experiment 1.

required for the incompatible assignment than for the compatible assignment. However, a compatibility effect is evident at each precuing interval.

A fourth significant interaction was the three-way interaction of hand $X$ finger $X$ interval $[F(3,45)=5.04, p<$ $.01]$. Mean reaction times for the three-way interaction are presented in Table 1. This interaction seems to be in the magnitude of change in reaction times, rather than a re- versal of the effect. For all hand and finger combinations, the patterns of reaction times were similar across all four precue intervals. That is, reaction times were slowest at the 0 -msec precue interval and were progressively faster for the 750- and 1,500-msec intervals, with the fastest reaction times occurring at the 3,000 -msec interval.

\section{Discussion}

Results of this experiment demonstrated that incompatible assignments resulted in slower reaction times than did compatible assignments. Additionally, the present experiment indicated that reaction times were slower in the mixed condition than in the same condition. In both cases, the differences are greater at shorter precue intervals. These results support the notion that more complex translations are required with incompatible assignments (Reeve \& Proctor, 1984, 1990) and the mixed conditions. Most important, the mixing of assignments within the $\mathrm{S}-\mathrm{R}$ set greatly slows reaction times, with the greatest effect being that on the subset with the compatible assignment (see Figure 2). In general, this result is consistent with Duncan's $(1977 \mathrm{a}, 1978)$ results. However, unlike in Duncan's studies, the use of the precue procedure in the present experiment specified to the subject which assignment and subset would be required for the response selection. The results of the present experiment suggest that the subset that was not precued influenced reaction times. This result indicates that the nonprecued subset is part of the mental representation on the basis of which the subject is making decisions, even after the possibility of those S-R sets being required has been eliminated. Thus, the nonprecued subset is involved in the translations for selecting the appropriate precued response. If this is the case, the stimulus and response sets are represented in some unified manner.

\section{EXPERIMENT 2}

The results of Experiment 1 suggest that translation processes from the entire $\mathrm{S}-\mathrm{R}$ set influence reaction times. That is, reaction times were affected by the nonprecued subset, thus indicating that all subsets influence translation processes. In Experiment 2, we sought to extend the findings from Experiment 1 by investigating the effect of the relationship between subset assignments with a reduced response set size. In Experiment 2, we examined compatibility effects as a function of the nature of the subset assignments and the length of the precue interval with a limited response set size. The conditions (same and mixed),

Table 1

Mean Reaction Times (in Milliseconds) for the Three-Way Interaction of Hand $\times$ Finger $\times$ Interval in Experiment 1

\begin{tabular}{llcccc}
\hline & & \multicolumn{4}{c}{ Precue Interval } \\
\cline { 3 - 6 } Hand & Finger & 0 & 750 & 1,500 & 3,000 \\
\hline Left & index & 561 & 415 & 398 & 381 \\
Left & middle & 565 & 452 & 408 & 386 \\
Right & index & 540 & 417 & 387 & 377 \\
Right & middle & 564 & 413 & 404 & 382 \\
\hline
\end{tabular}

Note-Precue interval is given in milliseconds. 
assignments (compatible and incompatible), and precue intervals $(0,750,1,500$, and $3,000 \mathrm{msec})$ were the same as those used in Experiment 1. However, in Experiment 2, the response set was composed only of responses made with the index and middle fingers of the right hand. Therefore, the response set size was reduced from the four responses in Experiment 1 to two responses in Experiment 2. As in Experiment 1, a precue provided advanced information about which assignment (compatible or incompatible) would be required for responding.

\section{Method}

Subjects. Subjects were 16 students who volunteered for participation in the study. Each subject received information regarding the nature of the experiment and signed informed consent forms. None of the subjects had participated in Experiment 1.

Apparatus. The apparatus was the same as that in Experiment 1, except that only two response keys, rather than four, were used. The response keys were adjacent to one another and were centered in front of the visual display. As with Experiment 1, the apparatus was interfaced with a TRS-80 Model III computer, which controlled stimulus presentations and recorded reaction times and performance errors.

Precues, assignments, and conditions. The warning, precue, and target stimuli were the same as those used in Experiment 1. Each subject placed the index and middle fingers of the right hand on the response keys. Subjects participated in four blocks of trials, one each on 4 consecutive days. As in Experiment 1, presentation order of blocks was random so that subjects did not perform in the same order of blocks. The four blocks of trials were the same as those in Experiment 1; that is, for one block, the assignment of the two leftmost and wo right-most stimuli to the fingers on the right hand was compatible. In another block, the assignment of the two left-most and the two right-most stimuli to the fingers on the right hand was incompatible. These two blocks represented the same condition, similar to the same condition in Experiment 1. In a third block, the assignment of stimuli to responses was compatible for the two left-most stimuli and incompatible for the two right-most stimuli. In a fourth block, the assignment of stimuli to responses was incompatible for the two left-most stimuli and compatible for the two right-most stimuli. The last two blocks represented the mixed conditions, similar to the mixed conditions in Experiment 1. Thus, as in Experiment 1, four stimuli were used to indicate assignments to two responses. The precue revealed which assignment would be required for that trial.

Procedure. The procedure for Experiment 2 was the same as the procedure in Experiment 1.

Design and analysis. Reaction times and response errors were obtained from each subject as a function of condition (same or mixed), assignment (compatible or incompatible), stimulus subset (left or right), finger (index or middle), and precue interval $(0,750,1,500$, or 3,000 msec). Stimulus subset refers to whether the precued subset was the right subset or the left subset. In Experiment 1 , the hand factor had been used; however, because only the right hand was used in this experiment, the data could not be separated by hand. Therefore, the new factor in Experiment 2 was stimulus subset. Reaction time data were analyzed in a 2 (condition) $\times 2$ (assignment) $\times 2$ (stimulus subset) $\times 2$ (finger) $\times 4$ (precue interval) analysis of variance with repeated measures on all factors.

Errors were calculated as in Experiment 1, with errors classified as either response errors or time constraint errors. Because errors were low (less than $1 \%$ ), no analyses were performed on these data.

\section{Results}

The analysis of reaction time data indicated three significant main effects. The first significant main effect was that of condition $[F(1,15)=51.15, p<.01]$. Reaction times were slower in the mixed condition $(540 \mathrm{msec})$ than in the same condition (441 msec). The second significant main effect was that of assignment $[F(1,15)=35.79, p<.01]$. Reaction times for incompatible assignments were $513 \mathrm{msec}$, and for compatible assignments, $470 \mathrm{msec}$. The third significant main effect was that of interval $[F(3,45)=86.13$, $p<.01]$. As expected, reaction times were slowest for the simultaneous onset $(0-\mathrm{msec})$ precue interval and became progressively faster as the interval increased to $3,000 \mathrm{msec}$ $(584,475,463$, and $440 \mathrm{msec}$ for precue intervals of 0,750 , 1,500 , and $3,000 \mathrm{msec}$, respectively). These results are consistent with those of Experiment 1 and with those of other precuing studies (Proctor \& Reeve, 1986; Reeve \& Proctor, 1984). The slower reaction times at the short precue intervals suggest that at the short interval subjects must work through some translations from the precue stimulus during the reaction time interval and that as the precue interval increases, the translations can be completed prior to the reaction time interval. These three factors are also involved in higher order interactions.

The analysis also indicated three significant two-way interactions. One was the condition $\times$ assignment interaction $[F(1,15)=6.27, p<.05]$. As can be seen in Figure 5 , there was a greater difference in reaction times between compatible and incompatible assignments for the same condition than for the mixed condition. Moreover, the mixed condition resulted in slower overall reaction times for both compatible and incompatible assignments. Note that the compatible reaction times for the mixed conditions are slower than the incompatible reaction times for the same condition. Because the three-way interaction for condition $\times$ assignment $\times$ interval was not significant $[F(3,45)<1.0]$, this pattern of reaction times occurred across all precue intervals. Therefore, when the nonprecued subset assignment is not consistent with the precued

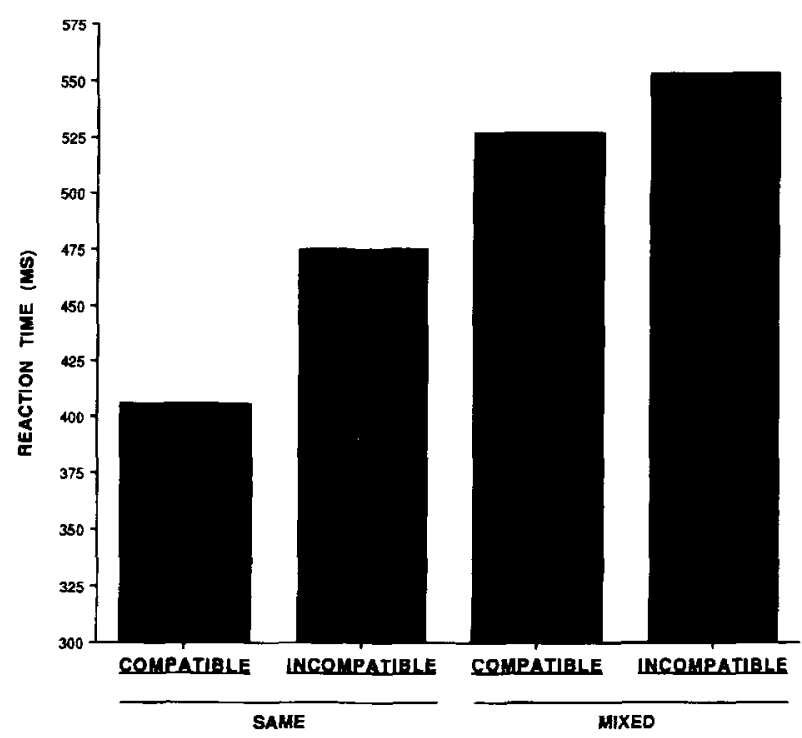

Figure 5. Mean reaction times as a function of condition (same/ mixed) and assignment (compatible/incompatible) in Experiment 2. 
subset assignment (i.e., the mixed condition), reaction times are slowed overall. Consistent with the results of Experiment 1 , this result indicates that the nonprecued subset was influencing the translation processes.

Another two-way interaction involved condition $\times$ interval $[F(3,45)=16.01, p<.01]$. As can be seen in Figure 6 , this interaction is due to the greater difference in reaction times between the same and mixed condition at the short precue intervals than at the long precue intervals (difference $=137,101,85$, and $72 \mathrm{msec}$ for intervals of 0,750 , 1,500, and 3,000 msec, respectively). As in Experiment 1, short precue intervals did not allow enough time for subjects to complete initial translation processes. Thus, translation processes occurred during the reaction time interval, resulting in longer reaction times as opposed to longer precue intervals. With longer precue intervals, some initial translations can occur during the precue interval. However, in the mixed condition more difficult translations are required, thus causing a greater difference in reaction times at shorter precue intervals than at longer precue intervals.

The final two-way interaction involved assignment $x$ finger $[F(1,15)=7.3, p<.01]$. There was a greater difference in reaction times between compatible and incompatible assignments for the index finger than for the middle finger, with the differences being 59 and $32 \mathrm{msec}$ for index and middle fingers, respectively.

The analysis indicated a significant three-way interaction of assignment $\times$ stimulus subset $\times$ finger $[F(1,15)=$ $19.55, p<.011$. The reaction times from the left-stimulus subset index-finger response in the compatible assignment were the fastest $(447 \mathrm{msec})$, and reaction times from the left-stimulus subset index-finger response in the incompatible assignment were the slowest $(520 \mathrm{msec})$.

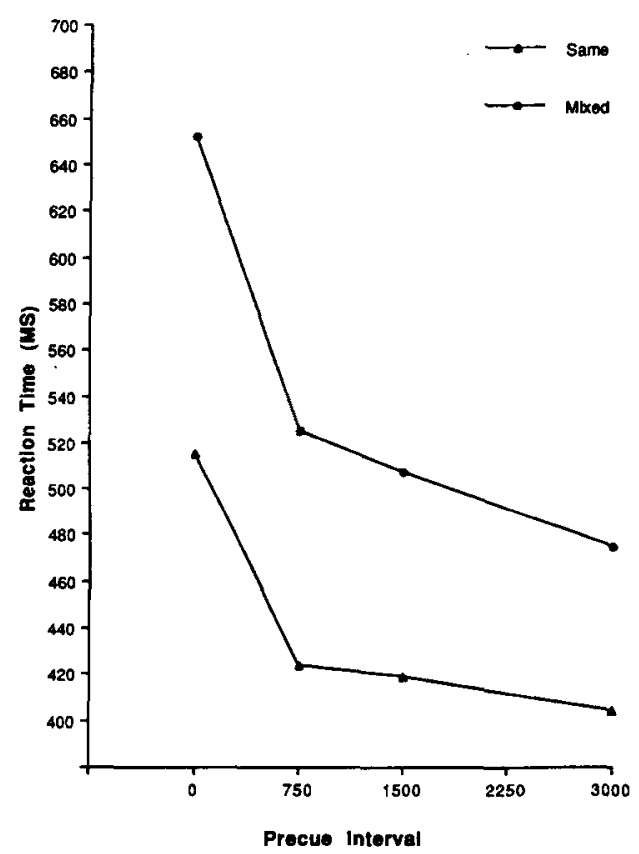

Figure 6. Mean reaction times as a function of condition (same/ mixed) and precue interval in Experiment 2.
There was a significant four-way interaction for assignment $\times$ stimulus subset $\times$ finger $\times$ interval $[F(3,45)=$ $3.31, p<.05]$. This interaction occurred because of the extremely fast reaction times for the compatible assignment, left-stimulus subset index-finger response at the 3,000msec precue interval $(395 \mathrm{msec})$ and the corresponding extremely slow reaction times for the incompatible assignment, left-stimulus subset index-finger response at the 0 -msec precue interval $(635 \mathrm{msec})$. However, for all comparisons, the compatibility effect is apparent, with incompatible assignments having slower reaction times than the compatible assignments.

\section{Discussion}

These results support previous findings of compatibility effects and an increase in reaction times with short precue intervals (Reeve \& Proctor, 1984). In addition, in this experiment as in Experiment 1 and Duncan's (1977a, 1978 ) studies, reaction times were slower in the mixed condition than in the same condition. For the precuing studies, this outcome suggests that when the nonprecued subset assignment is not consistent with the precued subset assignment, translations are more difficult, causing an increase in reaction times. Because reaction times are affected by the nonprecued subset, it seems that the translations are based on the mental representations of the entire S-R set.

\section{GENERAL DISCUSSION}

Duncan (1977a, 1977b, 1978) previously demonstrated that when different assignments are used for the S-R pairs within a set, reaction times are slower than when the same assignment, either compatible or incompatible, is used for all pairs. He concluded that the response decision processes are based on a system of rules that determine how the stimulus information is translated into the response information. Duncan emphasized that the properties of the entire set, in addition to the individual S-R pairs, must be considered if one is to understand response selection processes. In the present study, we extended Duncan's research by using the movement precuing procedure. This procedure is a useful method for examining the role of translation processes in S-R compatibility effects (Dornier \& Reeve, 1990; Hendrix, 1986; Larish, 1986; Proctor \& Reeve, 1986; Reeve \& Proctor, 1984, 1990). Relative to Duncan's research, the precue procedure allows for the examination of how subsets of responses may affect the $S-R$ translation processes. That is, when one subset is precued, the opportunity exists to eliminate the alternative noncued subset, especially with the longer precue intervals.

In Experiment 1, we examined the effects of same and mixed S-R subsets in a four-choice precuing task. The results indicated that reaction times were significantly slowed in the mixed condition and that those for the compatible assignments in the mixed condition were most affected (i.e., the significant condition $\times$ assignment interaction). This outcome is consistent with Duncan's (1977a, 1977b, 1978) findings. Although both condition (same/mixed) and as- 
signment (compatible/incompatible) interacted with precue interval, the interactions were only ones of magnitude of effect and not reversals of the effects of condition or assignment. More important, the three-way interaction of condition $\times$ assignment $\times$ interval was not significant, indicating that the condition $\times$ assignment effect was apparent at each interval. ${ }^{\text {I }}$ Thus, even with the longest precue interval $(3 \mathrm{sec})$, translation processes were influenced by the noncued S-R subset.

The results of Experiment 2, in which we used a reduced response set, closely followed those from the first experiment. Assigning the four stimulus locations to only two response locations did not alter the effects of mixing the $\mathrm{S}-\mathrm{R}$ assignments. As in Experiment 1, the reaction times were slower for the mixed condition than for the same condition, and the compatible assignment in the mixed condition was most affected (e.g., the condition $\times$ assignment interaction). Also, this effect occurred for all precue intervals. This finding replicates that from Experiment 1 , supporting the notion that the nonprecued subset is not eliminated from the translation processes.

Duncan (1977b) proposed that a system of rules is involved in the translation from stimulus to response in choice task situations and that the entire set of S-R pairs is involved in the translation process. Although considerable research on S-R compatibility has been conducted (see Proctor \& Reeve, 1990), the present study demonstrates the importance of Duncan's research and extends his findings. Duncan's emphasis on decision processes in the S-R translation is consistent with other explanations of S-R compatibility effects (e.g., Proctor \& Reeve, 1990; Reeve \& Proctor, 1990). These explanations have focused on the mental representations of the spatial S-R sets (e.g., Nicoletti \& Umiltà, 1985; Reeve \& Proctor, 1984; Wallace, 1971). The mental representation of $S-R$ sets could occur in a hierarchical arrangement or in an unified arrangement. In the hierarchical arrangement, as translations are made on the basis of the precue information, the process operations pass to another level. Thus, only the nonprecued subsets would be involved in the final translation processes. A prediction based on the hierarchical representation is that only components that are part of the precued subset would influence reaction times, given sufficient time to use the precue. If the $S-R$ pairs are represented hierarchically, then the nonprecued subset should not influence reaction times, because the initial translations based on the precue would eliminate the other subset. However, the results of the study indicate that the nonprecued subset does influence the translation processes, so a hierarchical representation of the $\mathrm{S}-\mathrm{R}$ set is not supported.

A unified, or single level, of representation would imply that all components of the S-R set are being mentally coded in such a way as to influence translation processes for all subsets. Although the precue reduced the four-choice task to a two-choice task, the nonprecued subset still influenced reaction times. With a unified representation of the $S-R$ set, processing includes translation requirements from all stimuli and responses, not just those which are part of the relevant subset, even with sufficient time to process the precue information (Reeve \& Proctor, 1984).

The present study demonstrated that the $S-R$ set is represented as a single entity and showed the importance of the relationship between the subsets in the translation processes. The results extend the work of Duncan (1977a, 1977b, 1978) by showing that even with advance information, the translation processes are influenced by alternative subsets that are not involved in the final response selection. One intriguing question that arises from this research is how is it that the precue which by reducing the set size can benefit reaction times (Reeve \& Proctor, 1984) but does not eliminate the influence of the nonprecued set.

\section{REFERENCES}

COHEN, J. (1988). Statistical power analysis for the behavional sciences (2nd ed.). Hillsdale, NJ: Erlbaum.

DorNiER, L. A., \& REEVE, T. G. (1990). Evaluation of compatibility effects in the precuing of arm and direction parameters. Research Quarterly for Exercise \& Sport, 61, 37-49.

DUNCAN, J. (1977a). Response selection errors in spatial choice reactions tasks. Quarterly Journal of Experimental Psvchology, 29, 415423

DuNCAN, J. ( 1977b). Response selection rules in spatial choice reaction tasks. In S. Dornic (Ed.), Attention and performance VI (pp. 49-61). Hillsdale, NJ: Erlbaum.

DUNCAN, J. (1978). Response selection in spatial choice reaction: Further evidence against associative models. Quarterly Journal of Experimental Psychology, 30. 429-440.

Dutta, A., \& Proctor, R. W. (1992). Persistence of stimulus-response compatibility effects with extended practice. Journal of Experimental Psychology: Learning, Memory. \& Cognition, 18, 801-809.

FitTS, P. M., \& SEEGER, C. M. (1953). S-R compatibility: Spatiai characteristics of stimulus and response codes. Journal of Experimental Psychology, 46, 199-210.

Goodman, D., \& Kelso, J. A. S. (1980). Are movements prepared in parts'? Not under compatible (naturalized) conditions. Journal of Experimental Psychology: General, 109,475-495.

Heister, G., Schroeder-Heister, P., \& Ehrenstein, W. H. (1990). Spatial coding and spatio-anatomical mapping: Evidence for a hierarchical model of spatial stimulus-response compatibility. In R. W. Proctor \& T. G. Reeve (Eds.), Stimulus-response compatihility: An integrated perspective (pp. 117-143). Amsterdam: Elsevier, NorthHolland.

HENDRIX, A. J.P. (1986). Compatibility of precuing and of S-R mapping in choice reactions. Acta Psychologica. 62, 59-88.

KLAPP, S. T. (1977). Response programming, as assessed by reaction time, does not establish commands for particular muscles. Journal of Motor Behavior. 9, 301-312.

Kornblum, S., Hasbrouce, T., \& Osman, A. (1990). Dimensional overlap: Cognitive basis for stimulus-response compatibility -A model and taxonomy. Psychological Review, 97, 253-270.

Ladavas, E. (1990). Some aspects of spatial stimulus-response compatibility in adults and normal children. In R. W. Proctor \& T. G. Reeve (Eds.), Stimulus-response compatibility: An integrated perspective (pp. 145-162). Amsterdam: Elsevier, North-Holland.

Ladavas, E., \& Moscoviteh, M. (1984). Must egocentric and environmental frames of reference be aligned to produce spatial $S-R$ compatibility effects? Journal of Experimenial Psychology: Human Perception \& Performance. 10, 205-215

LARISH, D. D. (1986). Influence of stimulus-response translations on response programming: Examining the relationship of arm, direction. and extent of movement. Acta Psvchologica, 61, 53-70. 
LEONARD, J. A. (1959). Tactual choice reactions: I. Quarterly Journal of Experimental Psychology, 11, 76-83.

Nicolettl, R., Anzola, G. P., Luppino, G., Rizzolatti, G., \& UMILTÀ, C. (1982). Spatial compatibility effects on the same side of the body midline. Journal of Experimental Psychology: Human Perceptien \& Performance, 8, 664-673.

NicoletTI, R., \& UMiLTÀ, C. (1985). Responding with hand and foot: The right/left prevalence in spatial compatibility is still present. Perception \& Psychophysics, 38, 211-216.

Proctor, R. W., \& REEve, T. G. (1986). Salient-feature coding operations in spatial precuing tasks. Journal of Experimental Psychology: Human Perception \& Performance, 12, 277-285.

Proctor, R. W., \& Reeve, T. G. (1988). The acquisition of task-specific productions and modifications of declarative representations in spatial-precuing tasks. Journal of Experimental Psychology: General, 117. 182-196.

Proctor, R. W., \& Reeve, T. G. (1990). Research on stimulus-response compatibility: Toward a comprehensive account. In R. W. Proctor \& T. G. Reeve (Eds.), Stimulus-response compatihility: An integrated perspective (pp. 483-494). Amsterdam: Elsevier, North-Holland.

Proctor, R. W., Reeve, T. G., \& VanZandt, T. (1992). Salient-features coding in response selection. In G. E. Stelmach \& J. Requin (Eds.), Tutorials in motor behavior I/ (pp. 727-741). Amsterdam: Elsevier, NorthHolland.

Reeve, T. G., \& Proc Tor, R. W. (1984), On the advanced preparation of discrete finger responses. Journal of Experimental Psychology: Human Perception \& Performance, 10, 541-553.

Reeve, T. G., \& Proctor, R. W. (1985). Non-motoric translation processes in the preparation of discrete finger responses: A rebuttal of Miller's (1985) analysis. Journal of Experimental Psychology: Human Perception \& Performance, 11, 234-240.

Rfeve, T. G., \& Proctor, R. W. (1990). The salient-features coding principle for spatial-and symbolic-compatibility effects. In R. W. Proc- tor \& T. G. Reeve (Eds.), Stimulus-response compatibility: An integrated perspective (pp. 163-180), Amsterdam: Elsevier, North-Holland. Rosenbaum, D. A. (1980). Human movement initiation: Specification of arm, direction, and extent. Journal of Experimental Psychology: General, 109, 444-474.

Rosenbaum, D. A. ( 1983 ). The movement precuing technique: Assumptions, applications, and extensions. In R. A. Magill (Ed.), Memory and control of action (pp. 231-274). Amsterdam: Elsevier, North-Holland.

Simon, J. R. (1969). Reactions toward the source of stimulation. Journal of Experimental Psychology, 81, 174-176.

Umiltà, C., \& Nicoletti, R. (1990). Spatial stimulus-response compatibility. In R. W. Proctor \& T. G. Reeve (Eds.), Stimulus-response compatibility: An integrated perspective (pp. 89-116). Amsterdam: Elsevier, North-Holland.

WALLACE, R. J. (1971). S-R compatibility and the idea of a response code. Journal of Experimental Psychology, 88, 354-360.

WeEks, D. J., \& Proctor, R. W. (1990). Salient-features coding in the translation between orthogonal stimulus and response dimensions. Journal of Experimental Psychology: General, 119, 355-366.

\section{NOTE}

1. The support for the unified representation is based on the nonsignificant three-way interactions (condition $\times$ assignment $X$ interval) in Experiments 1 and 2 . Although these analyses are derived from conditions with few degrees of freedom and relatively low power, the estimated effect sizes in Experiments 1 and 2 are only .06 and .045 , respectively (see Cohen, 1988). Thus, even with extremely large degrees of freedom, the effects would not have been significant.

(Manuscript received February 2, 1993; revision accepted for publication May 13, 1995.) 